\title{
EVALUATION OF MUSA ACUMINATA FRUIT AS A NATURAL SUPERDISINTEGRANT FOR TABLET FORMULATION
}

\section{GOPINATH E*}

\section{Department of Pharmaceutics, T. John College of Pharmacy, Bengaluru, Karnataka, India. Email: gopiphd2015@gmail.com}

Received: 27 April 2018, Revised and Accepted: 12 June 2018

\section{ABSTRACT}

Objective: The objective of the present work was to develop and evaluate a new, low-cost effective superdisintegrant from Musa acuminata fruit for tablet formulation.

Methods: The study involved collection of M. acuminata fruit powdered and evaluated for physicochemical properties. Propranolol Hcl was used as a model drug for tablet formulation. Different concentrations of $M$. acuminatea powder were used as superdisintegrant, and orodispersible tablet is prepared and evaluated. In the present study, sodium starch glycolate was used as synthetic superdisintegrant for comparative study.

Result: The powder was dark brownish and did not change throughout the study. The percentage porosity of powder was found to be $42.88 \%$ and angle of repose of was found to be $33.69^{\circ}$. The solubility study shows that the powders are sparingly soluble in water and disperse into individual particles. Total ash and acid insoluble ash values of powder were found to be 2.61 and $2.11 \% \mathrm{w} / \mathrm{w}$, respectively. The average weight of tablets was ranged from 101.42 to $103.52 \mathrm{mg}$ and averaged hardness was found to be $3.4 \mathrm{~kg} / \mathrm{cm}^{2}$. Moreover, the tablets exhibited acceptable friability. Disintegration time of all formulations was found to be in the range of 22-80 s and wetting time was found to be $07-18 \mathrm{~s}$.

Conclusion: From the study, it was concluded that M. acuminatea powder in the range of $2-12 \%$ can be used as superdisintegrant in orodispersible tablet formulation and shall be preferred as having nutritive value as well as cost profit in the development of orodispersible tablet than synthetic polymer.

Keywords: Musa acuminatea, Orodispersible, Superdisintegrant, Tablet.

(C) 2018 The Authors. Published by Innovare Academic Sciences Pvt Ltd. This is an open access article under the CC BY license (http://creativecommons. org/licenses/by/4. 0/) DOI: http://dx.doi.org/10.22159/ajpcr.2018.v11i10.26958

\section{INTRODUCTION}

Orodispersible or mouth dissolving or fast dissolving tablets are defined as a solid dosage form comprising a medicinal constituent, which instantaneously dissipates within seconds into the saliva when kept on the tongue [1]. Orodispersible tablets are like conventional tablets but are composed of special excipient called superdisintegrants, which facilitate them to break up the tablets within a minute in the mouth in the presence of saliva without any complexity of swallowing [2]. Disintegration plays a key role in improving the drug action and hence increases the patient compatibility. Disintegrates are the material that causes the rapid disintegration of the tablets into smaller particles that dissolve more quickly than in the absence of disintegrates. The term superdisintegrants, as it name proposes superior to disintegrants. Superdisintegrants are the substances which facilitate or increases the disintegration time (DT) even at low level, typically $1-10 \%$ by weight relative to the total weight of the dosage unit [3]. Musa acuminata is an evergreen perennial, not tree. The fruit bunch can have an average of 160 fingers with each finger around $2.5 \mathrm{~cm}-9 \mathrm{~cm}$ in size. The seeds of M. acuminata are around 5-6 $\mathrm{mm}$ in diameter. They are subglobose or angular and hard [4].

The objective of the present research work is to develop a new, lowcost effective, and easily available natural superdisintegrant from M. acuminata fruit to offer secure and effective drug delivery with better patient fulfillment.

\section{MATERIALS AND METHODS}

\section{Materials}

Propranolol hydrochloride was purchased from SD fine chem. Sodium starch glycolate, Microcrystalline Cellulose, Mannitol, and Magnesium stearate were purchased from Karnataka fine chem. Talc and Aerosil were purchased from Loba chemie Pvt. Ltd.

\section{Methods}

\section{Collection of M. acuminata powder}

The unriped fruit was purchased from the local market. The fruit was cleaned, and the peel was removed. Then, the pulp was dried and powdered using a mixer. The powdered substance was collected and stored in well-closed container for further studies.

\section{Physicochemical characterization of M. acuminata powder}

The properties of $M$. acuminata powder were evaluated for percentage yield, solubility, loss on drying, total ash and acid insoluble ash, $\mathrm{pH}$, angle of repose, bulk density, tapped density, Carr's Compressibility Index (CI), and Hausner's ratio (HR).

\section{Solubility test}

Solubility test was carried out using aqueous and non-aqueous solvents. In this test, various solvents are used and M. acuminata powder solubility was determined. A known amount of the solvent was put in a container then the M. acuminata powder was added and stirred vigorously.

\section{Determination of true density}

The true density is defined as the weight of the powder by true volume of the powder. Normally, true volume is determined as the volume of liquid it displaces; therefore, true density can be expressed as

True density, $\rho p=$ weight of the powder/volume of liquid it displaces by the powder $[5,6]$ 


\section{Determination of bulk density and tap density}

The bulk density of a powder is the ratio of the mass of an untapped powder sample and its volume including the contribution of the interparticulate void volume [7].

$$
\text { Tapped densities: }=\mathrm{M} / \mathrm{Vt}
$$

Where, $\mathrm{M}=$ Weight of powder, $\mathrm{Vb}=$ Volume occupied by powder without tapping, $\mathrm{Vt}=$ Volume occupied by powder after tapping [8]

\section{Determination of percentage porosity}

Whether the powder is porous or nonporous, the total porosity expression for the calculation remains the same. The percent porosity is expressed as

$\%$ porosity, $\varepsilon=$ true density-bulk density/true density $\times 100$

\section{Determination of HR and Carr's index}

The CI and HR may be calculated using measured values for bulk density ( $\rho$ bulk) and tapped density ( $\rho$ tapped) as follows:

$$
\begin{gathered}
\text { CI=100 } \times \rho \text { tap }-\rho \text { bulk } / \rho \text { tap } \\
\text { HR }=\rho \text { tap } / \rho \text { bulk }
\end{gathered}
$$

\section{Determination of angle of repose}

Angle of repose is defined as the maximum angle possible between the surface of the pile of powder and the horizontal plane. The angle of repose is designed by $\theta$ and given by equation

$$
\operatorname{Tan} \theta=\mathrm{h} / \mathrm{r}
$$

\section{Moisture content}

The moisture content was then determined as the ratio of weight of moisture loss to weight of sample expressed as a percentage

$$
\% M C=b-c / b-a \times 100
$$

a: Weight of weighing bottle, b: Weight of weighing bottle with $1 \mathrm{~g}$ of sample, c: Weight of weighing bottle with sample after drying at $105^{\circ} \mathrm{C}$ for $2 \mathrm{~h}[8,9]$.

\section{Determination of total ash}

$3 \mathrm{~g}$ of powder accurately weighed, in a suitable tared dish. Incinerate the material by gradually increasing the heat, not exceeding $450^{\circ} \mathrm{C}$, until free from carbon, cooled, and weighed. Total ash content can be calculated from

$$
\% \text { ash content }=\mathrm{c}-\mathrm{a} / \mathrm{b}-\mathrm{a} \times 100
$$

Weight of empty silica crucible $=(a)$, Weight of crucible with $3 \mathrm{~g}$ of sample $=(b)$, and Weight of crucible with ash $=(c)$

\section{DETERMINATION OF ACID-INSOLUBLE ASH}

The ash was boiled with $25 \mathrm{ml}$ of hydrochloric acid for $5 \mathrm{~min}$, and insoluble matter was collected in a sintered crucible, or on an ashless filter-paper, washed with hot and ignited at about $500^{\circ} \mathrm{C}$ to constant weight [10].

Total acid insoluble ash can be determined by

$$
\% \text { Acid insoluble ash }=(\mathrm{W} 2-\mathrm{W}) /(\mathrm{W} 1-\mathrm{W}) \times 100
$$

W: Weight of empty crucible, W1: Weight of crucible with dried material, W2: Weight of acid insoluble ash with a crucible.

\section{pH determination}

$1 \% \mathrm{w} / \mathrm{v}$ solution of sample was prepared by shaking powder in water for $5 \mathrm{~min}$, and $\mathrm{pH}$ is determined by digital $\mathrm{pH}$ meter.

\section{Formulation of tablet}

The calculated amounts of Propranolol HCL, superdisintegrant, microcrystalline cellulose, and mannitol as per the compositions in the table were accurately weighed, triturated well in a mortar and passed through sieve no 40. Finally, the correct amount of talc, magnesium stearate, and Aerocil was mixed with the powder blend for a further $2 \mathrm{~min}$. The obtained powder blend was compressed using a compression machine with $6 \mathrm{~mm} \mathrm{SC}$ punch by direct compression technique. The tablet weight was maintained to $100 \mathrm{mg}$. A minimum of 150 tablets were prepared for each batch (Table 1).

\section{Evaluation of tablets}

\section{General appearance}

The prepared tablets were evaluated visually for their appearance, texture, and tablets defects.

\section{Thickness}

Thickness of the tablets was calculated by the use of Vernier Calipers.

\section{Uniformity of weight}

Twenty tablets were weighed individually and collectively. Average weight was calculated from the total weight of all tablets. The individual weights were compared with the average weight.

\section{Hardness test}

The hardness was tested using Monsanto hardness tester. The average of the five determinations was determined and reported.

\section{Friability test ( $F$ )}

Roche friabilator was used to measure the friability of the tablets. It was rotated at a rate of $25 \mathrm{rpm} .20$ tablets were weighed collectively and placed in the chamber of the friabilator. After 100 rotations (i.e., in $4 \mathrm{~min}$ ), the tablets were taken out from the friabilator and intact tablets were again weighed collectively. Permitted friability limit is $1.0 \%$. The percent friability was determined by

$$
\mathrm{F}=\left(\mathrm{W}_{1}-\mathrm{W}_{2}\right) / \mathrm{W}_{1} \times 100
$$

Where, $\mathrm{W}_{1}=$ Weight of the tablets before friability test, $\mathrm{W}_{2}=$ Weight of the tablets after friability test [11].

\section{Wetting time}

The wetting time for the tablets is used as an indicator of the ease of tablet dissolution in the buccal cavity [12]. Six tablets were used for wetting time determination. A piece of tissue paper folded twice was placed in a small Petri dish (internal diameter $=6.5 \mathrm{~cm}$ ) containing $10 \mathrm{ml}$ of distilled water. A tablet was placed on the paper and the time for complete wetting of the tablet was determined.

\section{$D T$}

The in vitro DT of a tablet was estimated using disintegration test apparatus as per I.P. specifications. The time taken for the entire disintegration of the tablet with no residue remaining on the screen of basket rack was observed and noted [11].

\section{In vitro drug release}

In vitro, drug release studies of all the formulations were carried out using tablet dissolution test apparatus No 1 (as per I.P) at $100 \mathrm{rpm}$. $900 \mathrm{ml}$ of $0.1 \mathrm{M}$ hydrochloric acid was used as the dissolution medium with the temperature maintained at $37 \pm 2^{\circ} \mathrm{C}$. Samples were withdrawn 
Table 1: Formulation of tablet

\begin{tabular}{|c|c|c|c|c|c|c|c|}
\hline Formulation ingredient & PTM1 & PTM2 & РTM3 & PTM4 & PTM5 & PTM6 & PST7 \\
\hline Propranolol HCL & $20 \mathrm{mg}$ & $20 \mathrm{mg}$ & $20 \mathrm{mg}$ & $20 \mathrm{mg}$ & $20 \mathrm{mg}$ & $20 \mathrm{mg}$ & $20 \mathrm{mg}$ \\
\hline M. acuminata powder (\%) & 2 & 4 & 6 & 8 & 10 & 12 & - \\
\hline Sodium starch glycolate (\%) & - & - & - & - & - & - & 12 \\
\hline Microcrystalline cellulose & $24 \mathrm{mg}$ & $18 \mathrm{mg}$ & $16 \mathrm{mg}$ & $14 \mathrm{mg}$ & $12 \mathrm{mg}$ & $10 \mathrm{mg}$ & $10 \mathrm{mg}$ \\
\hline Mannitol & $50 \mathrm{mg}$ & $50 \mathrm{mg}$ & $50 \mathrm{mg}$ & $50 \mathrm{mg}$ & $50 \mathrm{mg}$ & $50 \mathrm{mg}$ & $50 \mathrm{mg}$ \\
\hline Talc & $2.8 \mathrm{mg}$ & $4.7 \mathrm{mg}$ & $4.7 \mathrm{mg}$ & $4.7 \mathrm{mg}$ & $4.7 \mathrm{mg}$ & $4.7 \mathrm{mg}$ & $4.7 \mathrm{mg}$ \\
\hline Magnesium stearate & $1 \mathrm{mg}$ & $3 \mathrm{mg}$ & $3 \mathrm{mg}$ & $3 \mathrm{mg}$ & $3 \mathrm{mg}$ & $3 \mathrm{mg}$ & $3 \mathrm{mg}$ \\
\hline Aerocil & $0.2 \mathrm{mg}$ & $0.3 \mathrm{mg}$ & $0.3 \mathrm{mg}$ & $0.3 \mathrm{mg}$ & $0.3 \mathrm{mg}$ & $0.3 \mathrm{mg}$ & $0.3 \mathrm{mg}$ \\
\hline Each tablet weight & $100 \mathrm{mg}$ & $100 \mathrm{mg}$ & $100 \mathrm{mg}$ & $100 \mathrm{mg}$ & $100 \mathrm{mg}$ & $100 \mathrm{mg}$ & $100 \mathrm{mg}$ \\
\hline
\end{tabular}

M. acuminate: Musa acuminate

Table 2: Physicochemical characterization of $M$. acuminata powder

\begin{tabular}{ll}
\hline Parameter & Result \\
\hline Description & Dark brownish powder \\
True density & $1.2 \mathrm{~g} / \mathrm{cm}^{3}$ \\
Bulk density & $0.714 \mathrm{~g} / \mathrm{cm}^{3}$ \\
Tap density & $0.769 \mathrm{~g} / \mathrm{cm}^{3}$ \\
HR & 1.0770 \\
Carr's index (\%) & $7.15 \%$ \\
\% porosity & $42.88 \%$ \\
Angle of repose & 33.69 \\
Moisture content & $6.64 \%$ \\
Total ash & $2.61 \%$ \\
Acid-insoluble ash & $2.11 \%$ \\
Loss on drying & $7.64 \%$ \\
PH & $7.1-7.6$ \\
Solubility & Sparingly soluble in water and glycerine. \\
& Insoluble in ethanol, chloroform, and ether. \\
& Practically insoluble in acetone. \\
\hline
\end{tabular}

M. acuminate: Musa acuminate, HR: Hausner's ratio

at a different time interval, diluted suitably with the same medium and analyzed at $290 \mathrm{~nm}$ using Shimadzu ultraviolet (UV) spectrophotometer. Limit: Not $<80 \%$.

\section{Assay}

A total of 20 tablets were crushed and weighed accurately a quantity of the powder containing about $20 \mathrm{mg}$ of propranolol hydrochloride and shaken with $20 \mathrm{ml}$ of water for $10 \mathrm{~min}$. To this, $50 \mathrm{ml}$ of methanol was added and shacked for a further $10 \mathrm{~min}$ and final volume was made to $100 \mathrm{ml}$ by adding a sufficient amount of methanol and filtered. From the filtrate, $10 \mathrm{ml}$ was withdrawn and made to $50 \mathrm{ml}$ with methanol and absorbance was measured at $290 \mathrm{~nm}$ using UV spectrophotometer [8].

\section{RESULTS AND DISCUSSION}

Physicochemical characterization of M. acuminata powder

The powder of the M. acuminata was dark brownish and did not change throughout our studies. The bulk and tapped density gave an insight on the packing and arrangement of the particles and the compaction profile of the materials. Porosity is estimates of the void (empty) spaces in solid substances and is a fraction of the volume of voids over total volume. Percentage porosity of M. acuminata powder was found to be $42.88 \%$. The angle of repose, a conventional characterization technique for pharmaceutical powder flow was evaluated. Height of the granules forming the cone $\mathrm{h}$ and the radius $\mathrm{r}$ of the base were measured and calculated. Flowability is indicated based on the angle of repose. A value of $<30^{\circ}$ indicates "excellent" flow whereas $>56^{\circ}$ indicates "very poor" flow. The intermediate scale indicates "good" ( $\theta$ between 31 and $\left.35^{\circ}\right)$, "fair" $\left(\theta\right.$ between 36 and $\left.40^{\circ}\right)$, "passable which may hang up" $(\theta$ between 41 and $\left.45^{\circ}\right)$, and "poor which must be agitated or vibrated" ( $\theta$ between 46 and $55^{\circ}$ ). Based on this, the angle of repose of powder was found to be 33.69 implying that M. acuminata powder had good flow property (Table 2).
HR is a measure of the interparticulate friction and important consideration in pharmaceutical powder flow properties. The HR of powder was found to be 1.07 implying that M. acuminata powder had excellent flow property. $\mathrm{CI}$ is significant in scale-up progression involving the materials as an excipient in pharmaceutical formulations. CI of M. acuminata powder was $7.15 \%$ implying that the powder had good flow property.

Moisture content of M. acuminata powder was found to be $6.64 \%$. The total ash and acid insoluble ash values of M. acuminata powder were found to be 2.61 and $2.11 \% \mathrm{w} / \mathrm{w}$, respectively. Ash value reflects the level of adulteration or handling of the drug. Adulteration by soli or other foreign is immediately identified as the total ash is usually composed of inorganic mixtures of carbonates, phosphates, silicates, and silica, therefore, the low value of total ash and acid insoluble ash obtained in this study indicated low level of contamination during the gathering and handling of crude M. acuminata powder.

$1 \% \mathrm{w} / \mathrm{v}$ suspension of M. acuminata powder in water gives a $\mathrm{pH}$ of 7.1-7.6. The near neutral $\mathrm{pH}$ of M. acuminata powder implies that when used in uncoated tablets it may be less irritating to the GIT. It may be a useful application in the formulation of acidic, basic, and neutral drugs.

Knowledge of $\mathrm{pH}$ of an excipient is an important parameter in determining its suitability in formulation since the stability and physiological activity of most preparation depends on $\mathrm{pH}$. The solubility of M. acuminata was performed using different polar and non-polar solvent, and the result shows that which are sparingly soluble in water and glycerin, insoluble in ethanol, chloroform, and ether, and practically insoluble in acetone.

\section{Evaluation of blended powder}

HR of blended powder was found to be in the range of 1.07-1.20 and for the optimized formulation code PTM6 the value was found to be 1.10 implying that powders have excellent flow property. HR is a measure of the interparticulate friction and important consideration in pharmaceutical powder flow properties. Carr's Index was found to be in the range of 7.31-16.67\% and for the optimized formulation code PTM6 the value was found to be 9.50 implying that powders have excellent flow property. $\mathrm{CI}$ is significant in scale-up progression involving the materials as an excipient in pharmaceutical formulations. Angle of repose of blended powder was found to be in the range of $28.36^{\circ}-36.68^{\circ}$ and for the optimized formulation code PTM6 the value was found to be $28.36^{\circ}$ implying that powders have excellent to flow property (Table 3).

\section{Evaluation of tablets}

The measured tablet weights ranged from 101.42 to $103.52 \mathrm{mg}$ implying that tablets are within uniform weights and low deviations from the official specifications. Crushing strength has been said to be the ability of tablets to withstand pressure or stress during handling, packaging, and transportation and the average tablet hardness was found to be $3.4 \mathrm{~kg} / \mathrm{cm}^{2}$. Moreover, the tablets exhibited acceptable friability that was $<1 \%$ in all tablet formulations. Tablet thickness has been said to vary with the density of the granules, applied pressure, and the speed of compression which, in turn, affects tablet disintegration 
and dissolution and from the results, the tablets were observed to have uniform thickness across the concentrations used and this can be attributed to their similar bulk and tapped densities and to the same compression force used during compression.

DT is very important for an oral dispersible tablet which is desired to be $<30 \mathrm{~s}$. This quick disintegration supports swallowing and plays a role in drug absorption in a buccal cavity, thus helps bioavailability. DT of all formulations was found to be in the range of 22-80 s and wetting time was found to be $07-18 \mathrm{~s}$ from these result it was concluded that as the concentration of superdisintegrant increases DT and wetting time decreases. Among all formulations, PTM6 contain $12 \%$ of $M$. acuminata as superdisintegrants was best than all other formulation and suitable for oral dispersible tablet formulation as they have minimum DT and wetting time. In vitro, dissolution studies of the prepared tablet were performed in $0.1 \mathrm{~N} \mathrm{Hcl}$, at $37 \pm 0.5^{\circ} \mathrm{C}$ and $100 \mathrm{rpm}$ by paddle method. All the formulations are complies with the limit of not $<80 \%$. Form the dissolution study, it was concluded that as the concentration of superdisintegrant increases, the percentage release drug release also increases (Tables 4 and 5, Figs. 1 and 2).

\section{CONCLUSION}

From the present studies, it can be concluded that natural superdisintegrants are suitable for the orodispersible tablet formulation. M. acuminata as $12 \% \quad \mathrm{w} / \mathrm{w}$ superdisintegrants showed better DT and percentage drug release than synthetic superdisintegrants. This study also concluded that M. acuminata can be preferred as superdisintegrants as they have nutritive value as well as cost-benefit in the development of orodispersible tablet than synthetic polymer.

\section{ACKNOWLEDGMENT}

I would like to thanks the Department of Pharmaceutics, T. John College of Pharmacy, Bengaluru, Karnataka, for research and support.

\section{AUTHOR'S CONTRIBUTIONS}

The author designed the work, developed the methodology, collected the data, and performed analysis work. The work was carried out at T. John College of Pharmacy, Bengaluru, Karnataka.

Table 3: Evaluation of blended powder

\begin{tabular}{|c|c|c|c|c|c|}
\hline Formulation code & Angle of repose $(\theta)$ & Bulk density $\left(\mathrm{g} / \mathrm{cm}^{3}\right)$ & Tapped density $\left(\mathrm{g} / \mathrm{cm}^{3}\right)$ & HR & Carr's Index (\%) \\
\hline PTM1 & 36.68 & 0.476 & 0.571 & 1.20 & 16.67 \\
\hline PTM2 & 28.36 & 0.476 & 0.526 & 1.10 & 9.53 \\
\hline PTM3 & 37.47 & 0.500 & 0.571 & 1.14 & 12.49 \\
\hline PTM4 & 28.36 & 0.487 & 0.526 & 1.07 & 7.31 \\
\hline PTM5 & 29.61 & 0.526 & 0.588 & 1.11 & 10.49 \\
\hline PTM6 & 28.36 & 0.476 & 0.526 & 1.105 & 9.50 \\
\hline PST7 & 29.62 & 0.512 & 0.571 & 1.110 & 10.39 \\
\hline
\end{tabular}

HR: Hausner's ratio

Table 4: Evaluation of tablets

\begin{tabular}{|c|c|c|c|c|c|c|c|}
\hline Formulation code & AVG weight (in mg) & Hardness $\left(\mathrm{kg} / \mathrm{cm}^{2}\right)$ & Friability (\%) & Thickness (mm) & DT (s) & Wetting time (s) & Assay \\
\hline PTM1 & $102.62 \pm 1.51$ & $3.4 \pm 0.51$ & 0.32 & 3.5 & $80 \pm 1.32$ & $18 \pm 1.53$ & 99.24 \\
\hline PTM2 & $101.42 \pm 2.08$ & $3.2 \pm 0.42$ & 0.47 & 3.5 & $65 \pm 1.21$ & $14 \pm 1.50$ & 98.44 \\
\hline PTM3 & $103.42 \pm 1.92$ & $3.5 \pm 0.12$ & 0.51 & 3.5 & $58 \pm 0.28$ & $13 \pm 0.31$ & 100.23 \\
\hline PTM4 & $101.42 \pm 1.73$ & $3.7 \pm 0.17$ & 0.58 & 3.5 & $42 \pm 0.23$ & $11 \pm 0.28$ & 101.42 \\
\hline PTM5 & $102.42 \pm 2.23$ & $3.4 \pm 0.12$ & 0.60 & 3.5 & $37 \pm 0.21$ & $09 \pm 0.21$ & 100.46 \\
\hline PTM6 & $101.42 \pm 2.12$ & $3.4 \pm 0.18$ & 0.61 & 3.5 & $22 \pm 0.24$ & $05 \pm 0.18$ & 100.43 \\
\hline PST7 & $103.52 \pm 2.12$ & $3.4 \pm 0.17$ & 0.73 & 3.5 & $27 \pm 0.22$ & $07 \pm 0.20$ & 103.65 \\
\hline
\end{tabular}

DT: Disintegration time

Table 5: Comparative in vitro dissolution study

\begin{tabular}{|c|c|c|c|c|c|c|}
\hline Formulation code & 0 (min) & 3 (min) & $6(\mathrm{~min})$ & $9(\mathrm{~min})$ & 12 (min) & 15 (min) \\
\hline PTM1 & 0.0 & 54.22 & 61.11 & 72.23 & 76.25 & 80.42 \\
\hline PTM2 & 0.0 & 59.24 & 68.19 & 72.12 & 78.17 & 81.31 \\
\hline PTM3 & 0.0 & 64.14 & 72.19 & 78.20 & 81.26 & 85.29 \\
\hline PTM4 & 0.0 & 73.12 & 78.22 & 81.41 & 83.44 & 86.23 \\
\hline PTM5 & 0.0 & 80.14 & 84.19 & 88.16 & 88.34 & 89.39 \\
\hline PTM6 & 0.0 & 85.45 & 89.98 & 92.38 & 92.49 & 93.31 \\
\hline PST7 & 0.0 & 86.35 & 89.42 & 91.43 & 91.98 & 92.24 \\
\hline
\end{tabular}

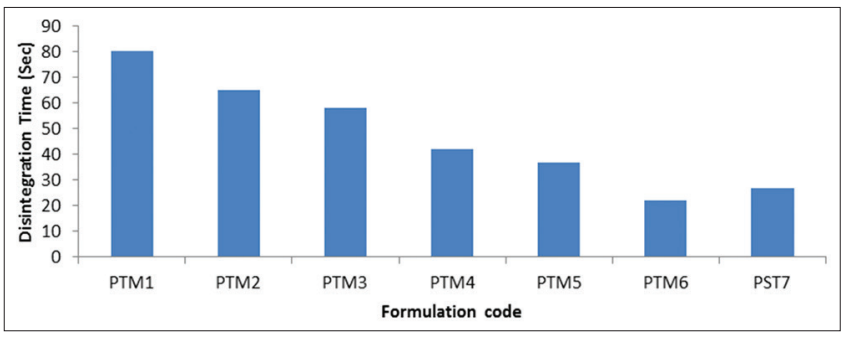

Fig. 1: Disintegration time for different formulation

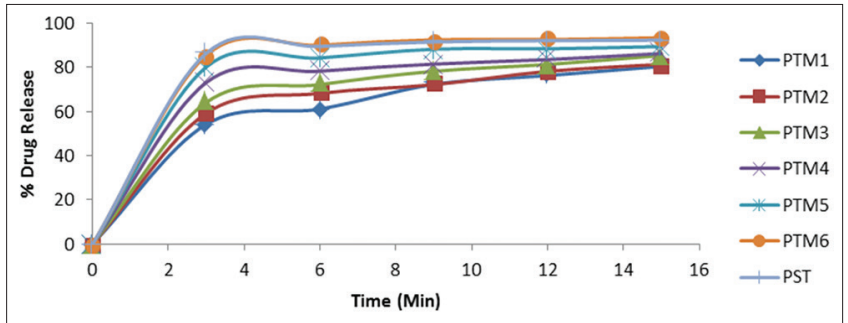

Fig. 2: Comparative in vitro dissolution study 


\section{REFERENCES}

1. Hiremath SP, Chidambar M. Formulation and evaluation of orodispersible tablets of a model anti-hypertensive drug. Int J Pharm Pharm Sci 2017;11:34-8.

2. Chang RK, Guo X, Burnside BA. Fast dissolving tablet. Pharm Tech 2000;24:52-8

3. Wadhavani AP. Indole 414 as novel superdisintigrants. Indian J Pharm Sci 1999;6:117-9.

4. Simmonds NW. Where our bananas come from. New Sci 2011;16:36-9.

5. WHO. Bulk density and tapped density of powders. Document 2012. No. QAS/11.450.

6. Mitul P, Jitendra P, Umesh M. Assessment of various pharmaceutical excipient properties of natural Moringa oleifera gum. Int J Pharm Life Sci 2012;3:1833-47.

7. Microx. Micromeritics for Pharmaceutical System, Density and
Porosity. Available from: http://www.micrx.com/Analytical-Services/ Density-and-Porosity.aspx.

8. United states Pharmacopoeia. US Pharmacopeial Convention 2005. p. 29-NF 24.

9. Indian Pharmacopoeia. Ministry of Health and Family Welfare. New Delhi: Government of India; 1996. p. 2.

10. WHO. The International Pharmacopoeia. Methods of Analysis: Methods for Materials of Plant Origin: Determination of Ash and Acidinsoluble Ash. Available from: http://www.apps.who.int/phint/en/p/ docf/.

11. David B, Paul B. Remington: The Science and Practice of Pharmacy. Philadelphia, PA: Lippincott Williams \& Wilkins; 2006.

12. Arti $\mathrm{M}$, sangeetha $\mathrm{G}$. In vitro-in vivo evaluation of fast-dissolving tablets containing solid dispersion of oxcarbazepine. Int J Pharm Pharm Sci 2016;8:124-31 